\title{
Characterization and Expression of the Glycoprotein Receptor for Murine Coronavirus
}

Kathryn V. Holmes and Richard K. Williams

\section{Introduction}

Coronaviruses are a family of large, enveloped, viruses with helical nucleocapsids and a single stranded genomic RNA of approximately $30 \mathrm{~kb}$ of message sense (Sturman and Holmes, 1983; Spaan et al., 1988). These viruses cause respiratory and/or enteric infections in man and many domestic animals (Wege et al., 1982). We are particularly interested in coronaviruses which infect the intestine. Pigs, cows, dogs, cats and mice are natural hosts for different coronaviruses each of which causes intestinal infection only in a single host species. Coronavirus infection results in a wide spectrum of clinical disease, ranging from inapparent infection of adult animals to severe, fatal neonatal diarrhea. Immunofluorescence studies show that in the intestine, coronavirus replication is limited to the epithelial cells, and multinucleated cells are frequently observed on the tips of the intestinal villi (Barthold et al., 1982; Barthold et al., 1985). We were interested in factors of the virus and the host which determine the species specificity and tissue tropism of these enterotropic coronaviruses.

As a model system to study the interactions of coronavirus virions with membranes of the normal target tissues from a naturally susceptible animal, we selected mouse hepatitis virus (MHV). MHV refers to a large group of serologically related coronaviruses which cause endemic and epidemic infections in mouse colonies (Lindsey, 1986). The tissue specificity of MHV strains is broader than that of most other coronaviruses. Various strains of MHV can infect the intestine, liver, spleen, respiratory tract, macrophages, and/or central nervous system (Virelizier et al., 1975; Knobler et al., 1981; Dubois-Dalcq et al., 1982; Barthold and Smith, 1989). Classical studies by Bang and his coworkers showed that inbred strains of mice differ markedly in susceptibility to MHV, and that macrophages from resistant mouse strains are resistant to infection with MHV in vitro (Bang and Warwick, 1960). These observations have been extended, and three strains of mice with reduced susceptibility to MHV have been identified: $\mathrm{C} 3 \mathrm{H}$ mice, in which only limited virus replication occurs and MHV infection is 
not fatal (Bang and Warwick, 1960; Arnheiter et al., 1982; Woyciechowska et al., 1984); A/J mice in which virus replication can be as extensive as in fully susceptible BALB/c mice, but with much less histopathology and disease (Arnheiter et al., 1982; Dindzans et al., 1986); and SJL/J mice, in which virus replication is profoundly reduced and MHV infection is not fatal (Smith $e t$ al., 1984; Knobler et al., 1985; Barthold and Smith, 1984).

We developed a solid phase virus binding assay to compare binding of the enterotropic and hepatotropic A59 strain of MHV to isolated membranes from MHV-susceptible BALB/c mice and MHV-resistant SJL/J mice (Boyle et al., 1987). MHV-A59 virus bound to intestinal brush border membranes and hepatocyte membranes isolated from BALB/c mice, but not to comparable membrane preparations from SJL/J mice. Treatment of BALB/c membranes with neuraminidase or detergents such as NP40 or deoxycholate did not inhibit virus binding, but treatment of membranes with proteases did inhibit virus binding. When membrane proteins from MHVsusceptible BALB/c mice, MHV-resistant SJL/J mice and semi-resistant

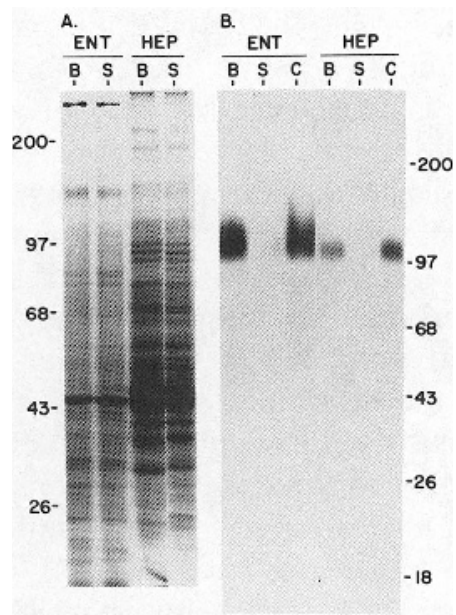

Figure 1. Virus-binding activity of membrane proteins from intestinal brush border membranes and hepatocyte membranes from strains of mice which differ in genetic susceptibility to mouse hepatitis virus (MHV). A. Coomassie blue staining of plasma membrane proteins from enterocytes (ENT) and hepatocytes (HEP) of BALB/c (lanes B) and SJ/J (lanes S) mice. B. Virus overlay protein blot assay of plasma membrane proteins from genetically susceptible BALB/c (lanes B), semi-resistant $\mathrm{C} 3 \mathrm{H}$ (lanes C), and resistant SJL/J (lanes S) mice was performed by probing electroblotted membrane proteins with MHV-A59 and detecting bound virus with anti-viral antibody and redioiodinated staphylococcal protein A. Molecular weight standards (in kDa) are shown on right. Reproduced from Boyle et al., 1987 with permission. 
C3H mice were reduced, separated by SDS-polyacrylamide gel electrophoresis, and blotted to nitrocellulose, MHV-A59 virions bound to a single band of $100-120 \mathrm{~K}$ from BALB/c and $\mathrm{C} 3 \mathrm{H}$ intestine and liver (Figure 1). No virus-binding band was observed in SJL/J membranes (Boyle et al., 1987). The virus-binding material from detergent-solubilized BALB/c intestine bound to several lectins (Holmes et al., 1987). These data showed that MHV-A59 binds to a 100-120 kDa glycoprotein in the membranes of the natural target tissues of highly susceptible BALB/c mice and semi-resistant C3H mice, but that membranes of MHV-resistant SJL/J do not contain a virus-binding glycoprotein. Thus, the profound resistance of SJL/J mice to MHV may be due to absence of a functional receptor for the virus (Boyle $e t$ al., 1987).

We developed monoclonal antibodies (MAb) directed against the MHV receptor glycoprotein (K. V. Holmes, in preparation). One of these, $\mathrm{MAb} \mathrm{CC} 1$, was particularly interesting. It bound specifically to the 100 to $120 \mathrm{kDa}$ glycoprotein in immunoblots of BALB/c liver and intestine membranes, and failed to recognize any glycoprotein in membranes from SJL/J mice (Figure 2; Williams et al, 1990). When mouse fibroblast cell lines were pretreated with MAb CC1 and then challenged with MHV-A59 virus, the cells were protected from infection (K. V. Holmes, in preparation). Binding of radiolabeled virus to cells was also blocked by pretreatment of cells with MAb CC1 (S. Snyder, in preparation). This anti-receptor MAb bound to mouse tissues with the same mouse strain specificity and tissue specificity observed in MHV-A59 virus infections. MAb CC1 showed strong immunofluorescent labeling of brush border membranes of BALB/c small intestine, and radiolabeled $\mathrm{MAb} \mathrm{CC} 1$ bound to membranes of colon, small intestine and liver of $\mathrm{BALB} / \mathrm{c}$ mice, but $\mathrm{MAb} \mathrm{CC} 1$ failed to bind to membranes from SJL/J mice (R. K. Williams, 1991).

MAb CC1 was used for affinity purification of the MHV receptor glycoprotein from Swiss Webster mouse liver (Figure 2; Williams et al., 1990). The isolated receptor was highly acidic, with a pI of approximately 4. It was also highly glycosylated, and treatment of the isolated receptor with peptide-N-glycanase $\mathrm{F}$ reduced the receptor to approximately $70 \mathrm{kDa}(\mathrm{R}$. K. Williams, in preparation). $\mathrm{N}$-terminal amino acid sequencing of the affinity purified MHV receptor was performed, and a synthetic peptide (NTR) corresponding to the first 15 amino acids of the receptor was synthesized. Anti-NTR antibody prepared in rabbits was used to immunoblot purified MHV receptor and intestinal and liver membranes from BALB/c and SJL/J mice (Figure 2B). Anti-NTR identified the 100 to $120 \mathrm{kDa}$ MHV receptor in the BALB/c membranes. However, unlike MHV virus or MAb CC1, antiNTR antibody identified a glycoprotein in the intestine and liver of SJL/J mice. In SDS-PAGE, this SJL/J glycoprotein migrated slightly faster than the MHV receptor glycoprotein of BALB/c mice. Binding of the anti-NTR antibody to BALB/c or SJL/J glycoproteins was specifically inhibited by absorption of the antibody with NTR peptide (Figure 2D). Thus, SJL/J mice 


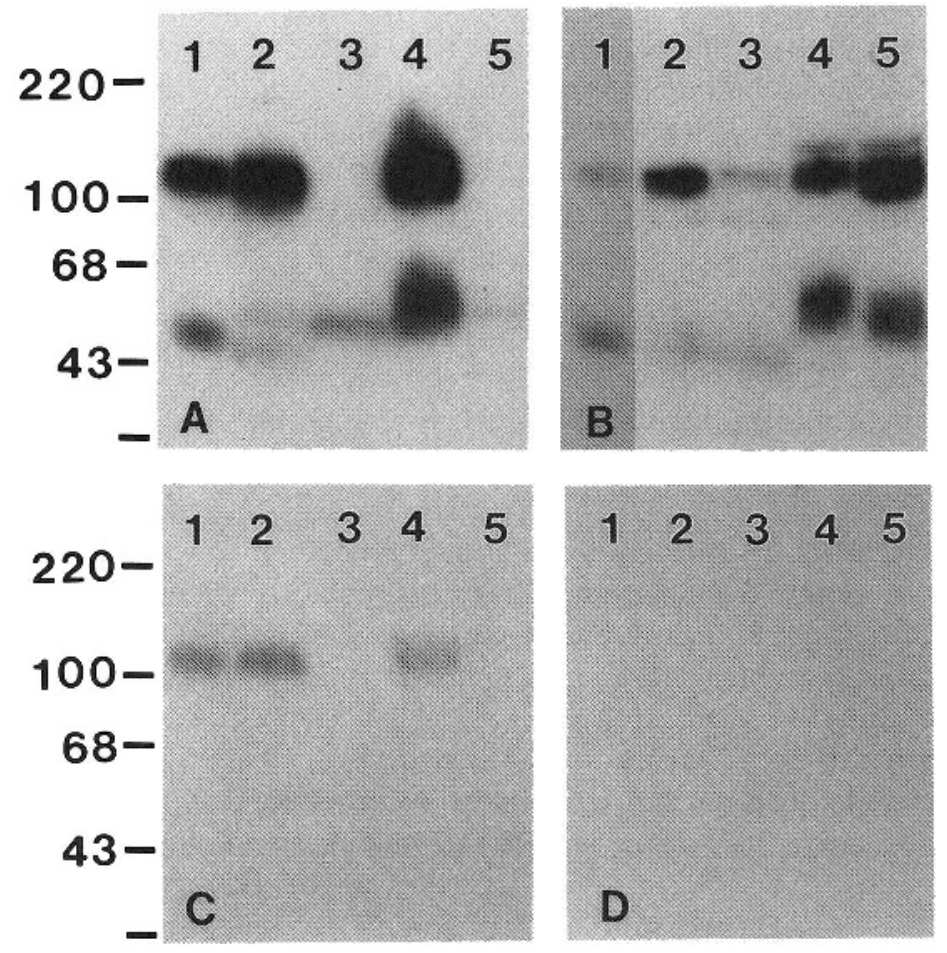

Figure 2. Immunoblot and virus overlay protein blot analysis of affinity-purified MHV receptor from Swiss Webster mouse liver and of BALB/c and SJ/J mouse liver and intestinal membranes. Panels A through D: Proteins were immunoblotted with anti-receptor MAb CC1 (A); antibody directed against the N-terminal peptide of the MHV receptor, anti-NTR (B); virus overlay protein blot, probed with MHV-A59 (C); or with anti-NTR that had been pre-adsorbed with 100ug of free NTR peptide per ml serum (D). Lanes: 1 , 3ng of affinity purified membrane protein; 2 and 3, 100ug of liver membrane P2 fraction from BALB/c and SL/J mice, respectively; 4 and 5, $100 u g$ of intestinal brush border membranes from BALB/c and SJ/J mice, respectively. Reproduced from Williams et al., 1990 with permission. 
express a glycoprotein which shares at least the $\mathrm{N}$-terminal epitope with the MHV receptor from BALB/c mice. This SJL/J molecule may be the homolog of the BALB/c glycoprotein which MHV recognizes as its receptor. The domain of the BALB/c glycoprotein which is recognized by MAb CC1 and MHV virus may be deleted or mutated in the SJL/J mouse so that the homologous glycoprotein fails to recognize these ligands. The normal cellular function of the MHV receptor glycoprotein from BALB/c mice is not yet known. Possibly the SJL/J homolog of the MHV receptor is able to perform its normal cellular function even though it cannot bind virus. This would be possible if the MHV-binding domain of the receptor glycoprotein is different from the domain required for its cellular function. Indeed, human immunodeficiency virus 1, rhinoviruses and Epstein Barr virus bind to their glycoprotein receptors at sites which are different from the functional domains of the glycoproteins (Jameson et al., 1988; Clayton et al., 1989; Lineberger et al., 1990; Racaniello, 1990; Carel et al., 1990; Barel et al., 1990).

A glycoprotein of approximately 48 to $58 \mathrm{kDA}$ which is immunologically cross-reactive with the MHV receptor glycoprotein was observed in immunoblots of intestine and liver membranes from both BALB/c and SJL/J mice (Figure 2; Williams et al., 1990). The 48 to $58 \mathrm{kDa}$ glycoprotein from BALB/c mice was recognized by anti-receptor MAb CC1 and anti-NTR antibody. It also bound MHV-A59 virions, but to a much lesser extent than the $110 \mathrm{kDa}$ receptor. Intestinal brush border membranes from SJL/J mice had a homologous glycoprotein of about $50 \mathrm{kDa}$ which was recognized by the anti-NTR antibody but not by anti-receptor MAb CC1 or by MHV-A59 virions. These results suggest that the $48-58 \mathrm{kDa}$ glycoproteins may be derived from the same genes as the 100-120 kDa MHV receptor of BALB/c mice and its SJL/J homolog. We do not yet know whether the smaller glycoproteins are derived by proteolytic cleavage of the 100 to $120 \mathrm{kDa}$ glycoproteins or whether they are products of alternative transcription of the genes for the larger proteins. The biological function(s) of the smaller glycoproteins are not yet known.

Solid phase assays for binding of MHV-A59 to intestinal brush border membranes from a variety of species, each of which serves as the natural host of a coronavirus, showed that MHV binds only to membranes from the intestine of MHV-susceptible or semi-resistant mice and not to intestinal brush border membranes from other species (Holmes et al., 1989). Anti-receptor MAb CC1 showed the same binding specificity (S. R. Compton, in preparation). Thus, MHV binds to a species-specific domain of the 100-120 kDa glycoprotein receptor. We are now studying the receptors for coronaviruses of other species to determine whether they are related to the MHV receptor glycoprotein. These studies will show whether various coronaviruses have evolved to recognize species-specific determinants of a glycoprotein homologous to the 100-120 kDa MHV receptor or whether they recognize different types of receptors on membranes from different species. 


\section{Acknowledgements}

We are grateful for the excellent technical assistance of C. Cardellichio, $\mathbf{P}$. Elia, and S. Wetherell and for consultation of our colleagues Drs. S. Compton, C. Dieffenbach, M. Pensiero, M. Frana, and Ms. G. Dveksler and S. Gagneten. This work was supported in part by PHS grants \# AI-18997, \# AI-25231, and \# AI-26075. The opinions expressed are the private views of the authors and should not be construed as official or necessarily reflecting the views of the Uniformed Services University of the Health Sciences or the Department of Defense.

\section{References}

Ang, F.B., and Warwick, A. (1960). Mouse macrophages as host cells for the mouse hepatitis virus and the genetic basis of their susceptibility. Proc. Natl. Acad. Sci. U.S.A. 46, 1065-1075.

Arnheiter, H., Baechi, T., and Haller, O. (1982). Adult mouse hepatocytes in primary monolayer culture express genetic resistance to mouse hepatitis virus type 3.J. Immunol. 129, 1275-1281.

Barel, M., Fiandino, A., Delcayre, A.X., Lyamani, F., and Frade, R. (1990). Monoclonal and anti-idiotypic anti-EBV/C3d receptor antibodies detect two binding sites, one for EBV and one for C3d on glycoprotein 140, the EBV/C3dR, expressed on human B lymphocytes. J. Immunol. 141, 1590-1595.

Barthold, S.W., and Smith, A.L. (1984). Mouse hepatitis virus strain-related patterns of tissue tropism in suckling mice. Arch. Virol. 81, 103-112.

Barthold, S.W., and Smith, A.L. (1989). Virus strain specificity of challenge immunity to coronavirus. Arch. Virol. 104, 187-196.

Barthold, S.W., Smith, A.L., Lord, P.F., Bhatt, P.N., Jacoby, R.O., and Main, A.J. (1982). Epizootic coronaviral typhlocolitis in suckling mice. Lab. Anim. Sci. 32, 376-383.

Barthold, S.W., Smith, A.L., and Povar, M.L. (1985). Enterotropic mouse hepatitis virus infection in nude mice. Lab. Anim. Sci. 35, 613-618.

Boyle, J.F., Weismiller, D.G., and Holmes, K.V. (1987). Genetic resistance to mouse hepatitis virus correlates with absence of virus-binding activity on target tissues. J. Virol. 61, 185-189.

Carel, J.C., Myones, B.L., Frazier, B., and Holers, V.M. (1990). Structural requirements for $\mathrm{C} 3 \mathrm{~d}, \mathrm{~g} / \mathrm{Epstein}-\mathrm{Barr}$ virus receptor (CR2/CD21) ligand binding, internalization, and viral infection. J. Biol. Chem. 265, 12293-12299.

Clayton, L.K., Sieh, M., Pious, D.A., and Reinherz, E.L. (1989). Identification of human CD4 residues affecting class II MHC versus HIV-1 gp120 binding. Nature 339, 548-551.

Dindzans, V.J., Skamene, E., and Levy, G.A. (1986). Susceptibility/resistance to mouse hepatitis virus strain 3 and macrophage procoagulant 
activity are genetically linked and controlled by two non-H2-linked genes. J. Immunol. 137, 2355-2360.

Dubois-dalcq, M.E., Doller, E.W., Haspel, M.V., and Holmes, K.V. (1982). Cell tropism and expression of mouse hepatitis viruses (MHV) in mouse spinal cord cultures. Virology 119, 317-331.

Holmes, K.V., Boyle, J.F., Weismiller, D.G., Compton, S.R., Williams, R.K., Stephensen, C.B. and Frana, M.F. (1987). Identification of a receptor for mouse hepatitis virus. Adv. Exp. Med. Biol. 218, $197-$ 202.

Holmes, K.V., Williams, R.K., and Stephensen, C.B. (1989). Coronavirus receptors. In:" Concepts in Viral Pathogenesis III" (Notkins, A., and Oldstone, M.B.A., Eds.) pp. 106-113. Springer-Verlag, New York.

Jameson, B.A., Rao, P.E., Kong, L.I., Hahn, B.H. Shaw, G.M. Hood, L.E. and Kent, S.B. (1988). Location and chemical synthesis of a binding site for HIV-1 on the CD4 protein. Science 240, 1335-1339.

Knobler, R.L., Dubois-dalcq, M., Haspel, M.V., Claysmith, A.P., Lampert, P.W., and Oldstone, M.B. (1981). Selective localization of wild type and mutant mouse hepatitis virus (JHM strain) antigens in CNS tissue by fluorescence, light and electron microscopy. $J$. Neuroimmunol. 1, 81-92.

Knobler, R.L., Linthicum, D.S., and Cohn, M. (1985). Host genetic regulation of acute MHV-4 viral encephalomyelitis and acute experimental autoimmune encephalomyelitis in (BALB/cKe $x$ SJL/J) recombinant-inbred mice. J. Neuroimmunol. 8, 15-28.

Lindsey, J.R. (1986). In:" Viral and Mycoplasmal Infections of Laboratory Rodents" (Bhatt, P.N., Jacoby, R.O., Morse, H.C.III, and New, A.E., Ed.) pp. 801. Academic Press, Inc., New York.

Lineberger, D.W., Graham, D.J., Tomassini, J.E., and Colonno, R.J. (1990). Antibodies that block rhinovirus attachment map to domain 1 of the major group receptor. J. Virol. 64, 2582-2587.

Racaniello, V.R. (1990). Cell receptors for picornaviruses. Curr. Top. Microbiol. Immunol. 161, 1-22.

Smith, M.S., Click, R.E., and Plagemann, P.G. (1984). Control of mouse hepatitis virus replication in macrophages by a recessive gene on chromosome 7. J. Immunol. 133, 428-432.

Spaan, W., Cavanagh, D., and Horzinek, M.C. (1988). Coronaviruses: Structure and genome expression. Review article. J. Gen. Virol. 69, 2939-2952.

Sturman, L.S., and Holmes, K.V. (1983). The molecular biology of coronaviruses. Adv. Virus. Res. 28, 35-112.

Virelizier, J.L., Dayan, A.D., and Allison, A.C. (1975). Neuropathological effects of persistent infection of mice by mouse hepatitis virus. Infect. Immun. 12, 1127-1140. 


\section{Holmes and Williams}

Wege, H., Siddell, S., and Ter Meulen, V. (1982). The biology and pathogenesis of coronaviruses. Curr. Top. Microbiol. Immunol. 99, $165-200$.

Williams, R.K., Jiang, G.-S. and Holmes, K.H. (1991). Receptor for mouse hepatitis virus is a member of the carcino embryonic anatigen family of glycoproteins. Proc. Natl. Acad. Sci. USA 88, 5533-5536.

Williams, R.K., Jiang, G.-S., Snyder, S.W., Frana, M.F., and Holmes, K.V. (1990). Purification of the 110-kilodalton glycoprotein receptor for mouse hepatitis virus (MVH)-A59 from mouse liver and identification of a nonfunctional, homologous protein in MHVresistant SJL/J mice. J. Virol. 64, 3817-3823.

Woyciechowska, J.L., Trapp, B.D., Patrick, D.H., Shekarchi, I.C., Leinikki, P.O., Sever, J.L. and Holmes, K.V. (1984). Acute and subacute demyelination induced by mouse hepatitis virus strain $\mathrm{A} 59$ in $\mathrm{C} 3 \mathrm{H}$ mice. J. Exp. Pathol. 1, 295-306. 